\title{
"We are on to something real and fundamental." An interview with Richard E. Cytowic
}

Richard E. Cytowic (MD) is a US-based neurologist and author. Dr Cytowic is rightfully considered to be a pioneering researcher of the phenomenon of synaesthesia. He has penned several publications, including the highly acclaimed books Synesthesia: A Union of the Senses $\left(1989 ; 2^{\text {nd }}\right.$ ed., 2002), The Man Who Tasted Shapes (1993), and Wednesday is Indigo Blue: Discovering the Brain of Synesthesia (co-authored with David Eagleman) (2009). Regarding the initial rejection in the 1980s of the legitimacy and significance of studying the condition, the contemporary resurgence in synaesthesia research is primarily Dr Cytowic's legacy. His scientific contribution is completed with educational projects. Synaesthesia has been the subject in Dr Cytowic's media appearances that were featured in numerous TV shows and documentaries. At present, R. Cytowic is exceptionally prolific, giving lectures for the public, writing blogs and participating in art projects.

We kindly asked Richard Cytowic to provide his opinion on several topics in today's synaesthesia research. The answers that we received via email make up an interview that we have the honor to publish in this special issue of T\&HS on synaesthesia.

Do you consider synesthesia as varieties of a unitary condition or as multiple disparate phenomena? Why?

This is a question I've asked myself since the beginning, in the late 1970s, when individuals with sensory couplings turned up with number forms as well (the latter now more precisely called spatial sequence synesthesia). I posed the question in the original series of forty-two individuals (see Table 1), even including a table, as I recall, of those with both synesthesia and number forms, and those with number forms alone.

I was a lumper rather than a splitter because the two experiences felt qualitatively similar, and I left it with readers as an open question. (You 
can see I am giving my temperament away with that "felt.") Back in the infancy of synesthesia's twentieth-century renaissance, a large part of the work was nosology, or classification, and one could get away with leaving loose ends. Time, however, now demands more precision. However, until we better understand synesthesia on a fundamental level - say genetically, or at a level on which we can at last arrive at an operational definition - it isn't possible to come down on one side of the unitary vs. disparate question with scientific certainty.

As I often tell students and audiences, a good scientist needs to be comfortable with ambiguity, uncertainty, and paradox, especially over long periods of time. It is highly possible that we won't have the final answer to synesthesia's protean character in my lifetime. That doesn't worry me. It is precisely the incompleteness after decades of delving that tells me we are on to something real and fundamental, something juicy in the way that answering one question raises ten more. Where will it end? Small wonder that young scholars get hooked by synesthesia's allure.

Table 1. Age of acquisition for cognitive traits and synesthesia types

\begin{tabular}{|c|c|c|c|c|c|c|c|}
\hline \multicolumn{8}{|c|}{ Age of acquisition of cognitive traits } \\
\hline $6 \operatorname{mos}$ & $\begin{array}{l}1 \mathrm{yr} \\
(12 \mathrm{mos})\end{array}$ & $\begin{array}{l}1.5 \mathrm{yr} \\
(18 \mathrm{mos})\end{array}$ & $\begin{array}{l}2 \mathrm{yr} \\
(24-30 \mathrm{mos})\end{array}$ & $\begin{array}{l}2.5-3 \text { yr } \\
(30-36 \text { mos })\end{array}$ & $\begin{array}{l}4 \mathrm{yr} \\
(36-48 \mathrm{mos})\end{array}$ & $\begin{array}{l}5 \mathrm{yr} \\
(48-60 \mathrm{mos})\end{array}$ & $\begin{array}{l}5-7 \text { yr } \\
(60-84 \text { mos })\end{array}$ \\
\hline $\begin{array}{l}\text { Phoneme } \\
\text { perception }\end{array}$ & $\begin{array}{l}\text { Word } \\
\text { fragments, } \\
\text { words }\end{array}$ & $\begin{array}{l}5-20 \text { word } \\
\text { vocabulary }\end{array}$ & $\begin{array}{l}\text { Oral speech: } \\
\text { phrases, object } \\
\text { names, } 1^{\circ} \\
\text { colors }\end{array}$ & $\begin{array}{l}\text { 3-word sentences; } 2^{\circ} \\
\text { colors; self-gender } \\
\text { comprehension; } \\
\text { mastery of food } \\
\text { names; naming 1- } \\
10^{\mathrm{a}} \text {; some alphabet }{ }^{\mathrm{b}}\end{array}$ & $\begin{array}{l}\text { Identifies with } \\
\text { same-sex parent; } \\
\text { cooperative play; } \\
\text { visual-tactile } \\
\text { cross-modal } \\
\text { associations }\end{array}$ & $\begin{array}{l}\text { Prefers gender } \\
\text { appropriate } \\
\text { games; attributes } \\
\text { characteristics to } \\
\text { others; dow, moy; } \\
\text { clock reading }\end{array}$ & $\begin{array}{l}\text { Reading, } \\
\text { writing }\end{array}$ \\
\hline \multicolumn{2}{|l|}{$6-12 \operatorname{mos}$} & \multicolumn{2}{|l|}{$18-24 \operatorname{mos}$} & \multicolumn{2}{|l|}{$36-42 \operatorname{mos}$} & \multicolumn{2}{|l|}{$48 \operatorname{mos}$} \\
\hline \multicolumn{2}{|c|}{$\begin{array}{l}\text { Food preferences } \\
\text { obvious }\end{array}$} & \multicolumn{2}{|c|}{ Food name use begins } & \multicolumn{2}{|c|}{$\begin{array}{l}1-10 \text { in order; numbers }>10 \text {; alphabet } \\
(42-48 \text { : knows out of sequence })^{\mathrm{d}}\end{array}$} & \multicolumn{2}{|l|}{ Early readers } \\
\hline \multicolumn{8}{|c|}{ Possible age of acquired synesthesia } \\
\hline \multicolumn{6}{|c|}{ 18-30: Tasted phonemes } & \multicolumn{2}{|c|}{ 30-60: Emotionally mediated } \\
\hline & & \multicolumn{4}{|c|}{ 30-36: Colored phonemes, colored tastes } & \multicolumn{2}{|c|}{$\begin{array}{l}\text { 34-40: Lexical (spoken words) } \\
\text { 36-60: Gendered/personified } \\
\text { graphemes }\end{array}$} \\
\hline & & & & \multicolumn{2}{|c|}{ 34-48: Colored graphemes } & & \\
\hline
\end{tabular}

Note mos $=$ months. dow $=$ knows days of week. moy $=$ knows months of year.

${ }^{\mathrm{a} B u t}$ does not yet know digits 1-10 out of order. ${ }^{\mathrm{b}} \mathrm{At} 30$ months, some kids know the alphabet by song. ${ }^{\mathrm{M}}$ Many number forms contain clock

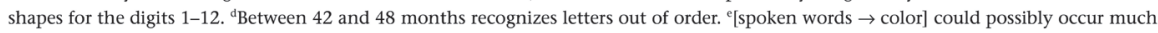
earlier; young speakers recognize the lexicality of words/nonwords before learning to write and read. It could occur shortly after colored graphemes but before phoneme-to-grapheme conversion. One question is whether word $\rightarrow$ color and grapheme $\rightarrow$ color synesthetes are early readers.

Having qualified my qualms, I lean toward the disparate side because what stands out are number forms, again. For example, over-learned sequences aren't "sensory" in the way that colored hearing is, nor are other common triggers such as graphemes, phonemes, and days of the week. From a functional MRI standpoint, the peak activations in colored hearing 
and spatial sequence synesthesia occur not only in disparate cortical areas but also on opposite sides of the brain. For some people, that would seem to settle the argument. You know that I am a longstanding critic of brain imaging, not per se, but because it too often leads to sloppy or reductionist thinking. fMRI greatly oversimplifies what occurs in the brain during a synesthetic experience (see Figure 1). Any idiot can, and does, point to a hot spot on a scan and say, "Here is the location of X." But that isn't remotely true. For instance, V4 activates during colored hearing, yes, but so does the anatomy underlying shape, size, movement, attention, spatial location, duration, and so on-except that we can't see every node in the network within the limits of current technology. Rather, we can say that synesthesia exists at any given time as the dominant process in the neural network underlying it. The experience is dynamic; what static scans capture are peak activations over the duration of the experimental task.

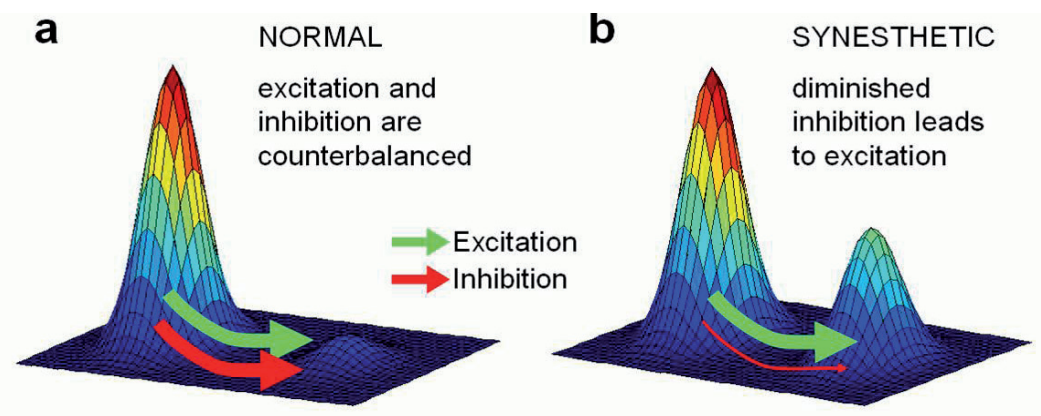

Figure 1. Peak activation during normal and synesthetic reactions (originally published in Cytowic and Eagleman, 2009). Courtesy of R.Cytowic

We now possess a rather hefty data set concerning the myriad aspects of synesthetic experience. Until we uncover an elementary phenomenon that unites its diverse phenomenology (and here, some hope, genetics might lead the way), we're faced with the real possibility that we are looking at the expression of separate phenomenon. Should we ever unearth that basic mechanism, I believe it will be simple and beautiful, as elegant as Maxwell's equations. It is this beauty that makes our study worthwhile.

Judging by a critical post you wrote in your blog on psychologytoday. com, you are following the ongoing trends in synesthesia research. What latest findings and proposals have inspired, surprised or puzzled you recently?

Imprinting - as in the case where mothers have saved refrigeratormagnet alphabet sets that years later prove to correspond to the grapheme 
colors of their offspring. At first, there was a single case; now there are a handful (Witthoft and Winawer 2013). Going forward prospectively now that we know what to ask, and sifting retrospectively through data sets such as the hefty one at synesthete.org, we will undoubtedly find more. By specifically looking for it, we may discover that imprinting accounts for a small percentage of grapheme synesthetes, perhaps up to ten percent. Such individuals will help us better understand what role memory plays in either inducing synesthesia, locking in the particular couplings first made in childhood, or both. This is exciting, but with a caveat.

For decades, one of the ways the establishment has denied synesthesia's reality has been by insisting that individuals were "just remembering" childhood associations from coloring books or refrigerator magnets. Much effort was spent refuting this. For instance, the late Jeffrey Gray (2007) went through round after round answering reviewers' objections only to be stonewalled at the end by the "just remembering" stance, which he took great pains to disprove. It is of course the nature of orthodoxy to dismiss what it does not understand, and I do not claim that memory isn't involved in synesthesia — of course it is, just as an elevated memory is one of the skills that the trait often bestows.

My dismay has to do with the "just." It is too easy to forget the enormous nuance inherent in the large, heterogeneous field. A headline on a recent Blog post at Psychology Today reads, "New research points to memory as a cause for this fascinating condition." What the wording implies, and what people will carelessly read, is that memory is the cause for synesthesia. They're "just remembering," so synesthesia isn't such a big deal after all. This shrug completely misses the point.

What was your most memorable initial misconception regarding synesthesia that was consequently dispelled?

A different dismissal was the claim that synesthesia was "merely" metaphoric speech, like poetry, or tropes such as "loud color." Because of this, I went out of my way to avoid any suggestion that language figured in synesthetic couplings. My stance was more an indication of the hostility I faced than my ignoring language's role outright. The National Enquirer, a supermarket tabloid, actually quoted me about an individual who tasted words. "Bizarre Medical Oddity Affects Millions!" the headline screamed. But I did not pursue cases of lexical synesthesia, so it was not until years later when Jamie Ward gave a detailed linguistic analysis of James Wannerton, who tastes words par excellence (Ward and Simner 2003), that the study of language in synesthesia took off. Ideas follow fashions just as hemlines do. 
In light of the recent genetic findings regarding synesthesia (its possible heterogeneity and polygenetics), how do you envision a resolution to the nature/nurture debate for synesthesia?

I don't, at least not any time soon. There are too many variables whose mechanisms we understand incompletely. An individual inherits (or has a spontaneous mutation for) a biological propensity to hyper-connect brain neurons, but then during the long period of human development must be exposed to cultural artifacts such as calendars, food names, and alphabets. How do the two interact? Uncovering imprinting at work in the fraction of instances involving refrigerator magnets gives a small piece of the puzzle. Simultaneously, it hints at how enormous that puzzle actually is.

To me, the amazing thing is that a nucleotide change in the sequence of one's DNA can alter perception. Whether it turns out to be polygenic or not, synesthesia offers a path to understanding subjective differences-how two people can see the same thing differently. To me, this is the deeper question than the genetic mechanism. In Wednesday is Indigo Blue, David Eagleman and I suggested looking at the timeline (see Table 1) of the customary ages at which infants reach various learning milestones and seeing whether given types of synesthesia appear at the same time or not. It is a simple question, but answering it would be involved, time consuming, and expensive.

This question has become more prominent in publications and discussions of neuroscientists, thus rendering philosophical and evolutionary strains to their reasoning. So, your voice on the matter can turn influential: Can any allo-animals be also synesthetes?

Since synesthesia is a first-person experience, we can't know. Channeling Thomas Nagel (1974), I can ask, What is it like to be a dog in its overwhelmingly olfactory world? I can ask, yet can hardly imagine that let alone enter the point of view of a synesthetic dog.

Experiments in ferrets that switch the auditory and visual inputs at the geniculate level of the thalamus cause animals to respond to the sensory mode that differs from the one in which they were trained. Does this show that non-human brains are plastic the way human ones are? Or are they inflexible, more like Sperry's frog that had its eye surgically rotated and which subsequently starved despite having tasty flies dangled in front of it? Even if we could answer intelligently, we would still be mute as to the animal's subjective experience. I would have to say that the question needs to be recast. What does the interrogator mean by an animal being synesthetic?

In your 2002 article, you compared synesthesia to a wrecking ball for the edifice of traditional theories of brain functioning (modularity, functionalism, objectivism), thus envisioning a paradigm shift forced by 


\section{synesthesia. What did you mean then and did it happen over these past 10 years?}

I meant what it sounds like. Rather than dismissing synesthesia because it was inexplicable according to orthodox theory - the "just," the "merely," the "crazy" accusations - perhaps it was theory that needed to give way. And so it did. It is impossible for Millennials or even Gen-Y's to understand the depth of hostility that reigned. Doctoral candidates would confide sotto voce how they wished they could investigate synesthesia but didn't dare risk their careers. Fortunately, that time is past, and we are much more tolerant of ideas today.

\section{References}

Cytowic, Richard E. 1993. The Man Who Tasted Shapes. New York: Putnam; 1998 (1st MIT edition). MIT Press; 2003. (Updated edition) Imprint Academic.

Cytowic, Richard E. 1997. Synaesthesia: Phenomenology and neuropsychology a review of current knowledge. In Simon Baron-Cohen and John E. Harrison (eds.), Synaesthesia: Classic and contemporary readings, 17-39. Oxford: Blackwell.

Cytowic, Richard E. 2002. Synaesthesia: A union of the senses (2nd ed.). New York: Springer-Verlag.

Cytowic, Richard E. and David M. Eagleman. 2009. Wednesday is indigo blue. Cambridge and London: MIT Press.

Gray, Jeffrey Alan. 2007. Consciousness: Creeping up on the hard problem. Paperback edition. Oxford University Press, USA.

Nagel, Thomas. 1974. "What Is it Like to Be a Bat?" The Philosophical Review 83(4): 435-450 (reprinted in 1979. Mortal Questions, 165-180. Cambridge University Press).

Ward, Jamie, and Julia Simner. 2003. "Lexical-gustatory synaesthesia: linguistic and conceptual factors." Cognition 89: 237-261.

Witthoft, Nathan, and Jonathan Winawer. 2013. "Learning, memory, and synesthesia." Psychological Science. DOI: 10.1177/0956797612452573 